\title{
New emerging therapies in the management of chronic lymphocytic leukemia (Review)
}

\author{
XIAO-LIN LI ${ }^{1}$ and CI-XIAN ZHANG ${ }^{2}$ \\ ${ }^{1}$ Department of Cardiology, Xuzhou Central Hospital, The Affiliated Xuzhou Hospital of Medical \\ College of Southeast University; ${ }^{2}$ Department of Cardiology, Xuzhou Clinical School \\ of Xuzhou Medical College, Xuzhou, Jiangsu 221009, P.R. China
}

Received March 30, 2016; Accepted July 25, 2016

DOI: $10.3892 / \mathrm{ol} .2016 .5108$

\begin{abstract}
Chronic lymphocytic leukemia (CLL) is considered incurable despite advances in management strategies. New drugs targeting cell pathways are currently being developed for the efficient management of CLL. Various strategies involving different targets have been developed, or are currently in the developing stage. A search was conducted in the electronic database PubMed, for pre-clinical as well as clinically controlled trials reporting various strategies against CLL currently under investigation. Novel strategies included use of antibodies, small cell inhibitors, such as spleen tyrosine kinase, LYN, cyclindependent kinase, and histone deacetylase inhibitors. The present review examined these new and emerging strategies for the efficient management of CLL. The review involves a discussion of novel strategies being examined worldwide against CLL, including anti-CD20, anti-CD37, anti-CD23, anti-CD40, SYK/LYN inhibitors, BTK inhibitors, p13k inhibitors and recent developments such as the use of cyclin-dependent kinase inhibitors/histone deacetylase inhibitors.
\end{abstract}

\section{Contents}

1. Introduction

2. Anti-CD20

3. Anti-CD37

4. Anti-CD23

5. Anti-CD40

6. Small targeted molecules

7. New and emerging therapies

8. Conclusions

Correspondence to: Dr Xiao-Lin Li, Department of Cardiology, Xuzhou Central Hospital, The Affiliated Xuzhou Hospital of Medical College of Southeast University, 199 South Jiefang Road, Xuzhou, Jiangsu 221009, P.R. China

E-mail: pqywj44@163.com

Key words: chronic lymphocytic leukemia, targeted therapy, leukemia, antibodies, immunotherapy

\section{Introduction}

Chronic lymphocytic leukemia (CLL) is usually characterized by the accumulation of mature B-lymphocytes in the blood, bone marrow and lymphoid tissue (1). The nature of the disease is heterogeneous in biological and clinical terms. Affected patients do not require any therapy, while other patients are required to undergo an aggressive course of therapeutic approaches, which may exhibit poor response. Despite numerous scientific endeavors the possibility of relapse may be observed in almost all patients (2). Furthermore, the etiology of CLL remains to be determined. The most obvious risk factor observed is age. Nevertheless, hereditary factors due to family history of CLL may constitute feasible risk factors (3). Additionally, environmental factors are responsible for spread of CLL, including exposure to pesticides, high magnetic fields, farming and animal breeding (4). Some viruses have also been observed to be associated with CLL occurrence (5).

The presentreview assessed the latest therapeutic approaches currently being developed for the better management of CLL. In recent approaches, the utilization of monoclonal antibodies has emerged for the efficient management of CLL especially in combination with chemotherapy (rituximab, ofatumumab, obinutuzumab) or as single-agent therapy in the refractory setting $(6,7)$. The details of the important antibodies in use are to be discussed in the subsequent sections of this review. Furthermore, inhibitors targeting small molecules during CLL including spleen tyrosine kinase (SYK), LYN, BTK, and P13K inhibitors are to be discussed.

The aim of the review was to update knowledge of concerned readers including medical physicians, or scientist working in the area of CLL management in order to stimulate planning of better studies in future for the advanced and efficient management of CLL.

\section{Anti-CD20}

Antibodies targeting CD20 are under investigation for their therapeutic potential against CLL (7). The two types, type I and II mAbs, differ in their CD20 binding and activation of cell death pathways (7). Type I CD20 antibodies are associated with stronger complement-dependent cytotoxicity (CDC) but with fewer cell deaths. The occurrence of resistance to type I mAbs 
is associated with the loss of CD20 by 'shaving' or antibody internalization. Type II CD20 antibodies have a lower CDC effect but can induce increased direct cell death. Less resistance to therapy can be expected due to less antigenic internalization which may prolong the presence of the antibody on the cell surface, thereby increasing antibody-dependent cellular cytotoxicity (ADCC) (7). Rituximab is a type I chimeric anti-CD20 antibody that exerts its function via CDC and ADCC (8). Obinutuzumab is the first humanized glycoengineered type II mAb. Preclinical studies showed a superior killing activity and a greater B-cell depletion than rituximab (7). The toxicity profile was acceptable (transient neutropenia, thrombocytopenia) with a dose-dependent incidence of adverse effects. Thus, obinutuzumab monotherapy appears active in advanced CLL but shows a higher toxicity than rituximab. The optimal dose, schedule of administration and duration of treatment remains elusive and further studies are required to gain this information. Given the encouraging results with obinutuzumab combined with chlorambucil first-line treatment, other combinations are under investigation (9). A non-randomized study in previously untreated patients that investigated obinutuzumab in combination with FC or bendamustine confirmed better and more efficient results (10).

\section{Anti-CD37}

CD37 is a transmembrane protein present normally on mature $\mathrm{B}$ cells and is usually upregulated in CLL cells. Otlertuzumab (TRU-016) is a CD37-specific protein drug that is applied in clinic (11). A phase I study evaluating safety in 223 CLL patients did not identify any maximum-tolerated dose. The most frequent adverse events (infusion-related reaction, fatigue, nausea and diarrhea) were not dose related. However, as a single agent CD37 appears to have modest clinical activity in CLL [partial response $23 \%$ and complete response (CR) 0\%] and lower response rates in $17 \mathrm{p}$-deleted patients (16\%) (12). Responses were more common in untreated or less treated patients. Preclinical data indicated additive or synergistic activity with rituximab and bendamustine (13). The combination of otlertuzumab and bendamustine compared to bendamustine as monotherapy was investigated in 225 relapsed CLL patients and appeared tolerable with an overall response rate (ORR) of $80 \%$ (20\% CR) compared to $42 \%$ (4\% CR) for bendamustine alone (14). However, no patients with $17 \mathrm{p}$ deletion responded. In addition, whether otlertuzumab combined with bendamustine is better than bendamustine, rituximab remains unknown. Otlertuzumab combined with rituximab was investigated in previously untreated CLL and seems a feasible strategy, albeit there are currenty no data on the response rates (15).

\section{Anti-CD23}

CD23 is expressed on B cells with significantly higher expression rates as compared to $\mathrm{B}$ cells with decreased expression (11). Lumiliximab is a chimeric anti-CD23 antibody that mediates cell death through ADCC and CDC. Preclinical studies have shown antitumor activity against CLL cells. However, a phase III trial comparing fludarabine, cyclophosphamide and rituximab (FCR) combined with lumiliximab to FCR was not successful due to the low benefit in relapsed CLL (16).

\section{Anti-CD40}

CD40 is a transmembrane protein expressed on normal and malignant B cells (17). CLL has been reported to cause activation of the PI $3 \mathrm{~K}$ and $\mathrm{NK} \kappa \mathrm{B}$ pathways and inhibition of apoptosis. Lucatumumab is an anti-CD40 antibody that triggers ADCC and inhibits CD40L-induced proliferation in vitro (11). However, phase I data in the relapsed setting showed mainly stable disease as best response (17). Anti-CD19 is a transmembrane protein expressed strictly in B cells and has been reported to enhance signaling depending on B-cell receptor $(\mathrm{BCR})$ antigen stimulation.

\section{Small targeted molecules}

SYK and LYN inhibitors. SYK and LYN are non-receptor kinases activated following BCR ligand binding. They activate signaling pathways downstream of BCR, and modulate cell adhesion and chemotaxis of $\mathrm{B}$ cells and are therefore critical for survival and maintenance $(18,19)$. Fostamatinib is an orally reversible, relatively selective SYK inhibitor. In vitro, its bioactive form is known as R406. It has also been observed to be well tolerated (20). Dasatinib is another reversible pan-Src kinase inhibitor that has been reported to inhibit a variety of other kinases, such as LYN and BTK. The low response rate compared to other kinase inhibitors targeting BTK or PI3Kס may be due to the function of LYN as a negative regulator of BCR signaling. Bafetinib (INNO-406) is an orally available LYN kinase inhibitor. Administration of a higher dose is currently under investigation (21).

BTK inhibitors. Ibrutinib (PCI-32765) is the first human BTK inhibitor in vitro and in vivo (22). Both in vitro and in patients, ibrutinib impaired microenvironment-induced survival and proliferation as well as the release of and migration towards tissue-homing chemokines $(23,24)$. This inhibitor also impairs integrin signaling, thereby affecting CLL cell adhesion (23). Ibrutinib is generally well tolerated as a single agent and in various combination, even in a heavily pretreated and elderly population with comorbidities (25). The most common adverse effects include fibrillation, and serious bleeding, such as subdural hematoma (26). ONO-4059 is another available BTK inhibitor that binds covalently to BTK and is more specific than ibrutinib (27).

PI3K inhibitors. Idelalisib (CAL-101) is an orally available, highly specific and reversible inhibitor of PI3K (26). Idelalisib causes inhibition of AKT activation, which decreases myeloid cell leukemia sequence 1 (MCL-1) expression and promotes apoptosis in CLL cells in vitro and in patients $(28,29)$. Conversely, it shows minimal cytotoxicity against normal T and NK cells (28). Idelalisib inhibits chemotaxis towards chemokines, pro-survival cytokines and secretion of chemokines (CCL3/4) from CLL cells in vitro as well as in treated patients. Idelalisib decreases CLL adhesion by interfering with CD49d/VCAM-1 binding which may explain the redistribution of CLL cells observed in treated patients (30). Idelalisib may also have immune modulating capacity as inhibition of regulatory $\mathrm{T}$ cells has been observed in vitro (31). The most common toxicities included fatigue, 
rash, pyrexia and cough together with pneumonia and pneumonitis (32). Thus, idelalisib appears to be active in high-risk patients.

BCL-2 inhibitors. BH3 mimetics are small molecules. Navitoclax (ABT-263) is a BH3-mimetic targeting preferentially BCL-2 and BCL-xL proteins. Additionally, early phase I data on navitoclax in combination with bendamustine, rituximab showed promising results (ORR $\leq 81 \%$ including CRs) (33). Neutropenia was the most common side effect, affecting at least one third, however, febrile neutropenia was not frequent (6\%). Non-hematological side effects (diarrhea, nausea and fatigue) affected approximately one third of the patients (34).

\section{New and emerging therapies}

Cyclin-dependent kinase $(C D K)$ inhibitors. Cyclins are the known rheostats of the cell cycle. Their expression fluctuates regularly and they require the presence of a CDK to accomplish their regulatory work. Several inhibitors may target cDKs to decrease anti-apoptotic proteins, and thereby induction of programmed cell death in CLL cells in a p53-independent manner (35) The broad CDK inhibitor flavopiridol (alvocidib) is the most comprehensively studied compound in this category of drugs. The pan-CDK inhibitor dinaciclib (SCH 727965) has shown potent pre-clinical activity against CLL cells independently of high-risk genomic features by downregulating the mRNA and protein expression of MCL-1 (35). However, it appears ineffective at overcoming the protective effect between CLL and stromal cells. Dinaciclib achieved an ORR of 58\% and a progression-free survival of 16 months in patients with relapsed or refractory CLL in a phase I/II trial involving 285 patients. The ORR for patients with $17 \mathrm{p}$ deletion was similar (57\%). P1446A is a novel orally active CDK inhibitor that has shown pre-clinical activity in CLL. However, samples carrying $17 \mathrm{p}$ deletion showed decreased sensitivity (36). The most frequent related toxicity appears to be myelosuppression and the associated increased risk of tumor lysis syndrome (37). Thus, CDK inhibitors appear to be an effective choice as single agents and in combination with chemotherapy in relapsed and refractory CLL. However, more studies are required for their establishment as a concrete therapeutic approach.

Histone deacetylase (HDAC) inhibitors. HDACs, in several isoenzyme classes, are overexpressed in CLL (38). HDACs mediate the epigenetic silencing of certain miRNAs that are critical tumor suppressors. Inhibition of HDACs in vitro induces the expression of these miRNAs followed by a decreased level of MCL-1 and induction of cell death (39), i.e., HDAC inhibitors have the ability to reverse epigenetic alterations associated with CLL cell survival. Mocetinostat (MGCD0103) is an orally available HDAC inhibitor that demonstrated efficacy in vitro in human cancer cell lines (40). It modulated the expression of critical autophagy genes that possibly contribute to autophagy impairment in CLL cells (41). However, the clinical effectiveness in CLL appears to be limited, with no responses in CLL high-risk patients.

\section{Conclusions}

At present, investigations regarding the development of efficient targeted therapy for the management of CLL patients are ongoing. Subsequently, application of these new and emerging drugs remains to be confirmed.

\section{References}

1. Nabhan C, Chaffee KG, Slager SL, Galanina N, Achenbach SJ, Schwager SM, Kay NE and Shanafelt TD: Analysis of racial variations in disease characteristics, treatment patterns, and outcomes of patients with chronic lymphocytic leukemia. Am J Hematol: Mar 25, 2016 (Epub ahead of print).

2. Hallek M and Pflug N: Chronic lymphocytic leukemia. Ann Oncol 21 (Suppl 7): vii154-vii164, 2010.

3. Goldin LR, Pfeiffer RM, Li X and Hemminki K: Familial risk of lymphoproliferative tumors in families of patients with chronic lymphocytic leukemia: Results from the Swedish Family-Cancer Database. Blood 104: 1850-1854, 2004.

4. Feychting M, Forssén U and Floderus B: Occupational and residential magnetic field exposure and leukemia and central nervous system tumors. Epidemiology 8: 384-389, 1997.

5. Ohyashiki JH, Abe K, Ojima T, Wang P, Zhou CF, Suzuki A, Ohyashiki K and Yamamoto K: Quantification of human herpesvirus 6 in healthy volunteers and patients with lymphoproliferative disorders by PCR-ELISA. Leuk Res 23: 625-630, 1999.

6. Laribi K, Tempescul A, Ghnaya H, Denizon N, Besançon A, Anghel A, Farhi J, Truong C, Lemaire P, Poulain S, Bolle D, Ianotto JC and Baugier de Materre A: The bendamustine plus rituximab regimen is active against primary nodal marginal zone B-cell lymphoma. Hematol Oncol: Jul 22, 2016 (Epub ahead of print).

7. Rioufol C and Salles G: Obinutuzumab for chronic lymphocytic leukemia. Expert Rev Hematol: 1-11, 2014

8. Cartron G, de Guibert S, Dilhuydy MS, Morschhauser F, Leblond V, Dupuis J, Mahe B, Bouabdallah R, Lei G, Wenger M, et al: Obinutuzumab (GA101) in relapsed/refractory chronic lymphocytic leukemia: Final data from the phase $1 / 2$ GAUGUIN study. Blood 124: 2196-2202, 2014.

9. Goede V, Fischer K, Busch R, Engelke A, Eichhorst B, Wendtner CM, Chagorova T, de la Serna J, Dilhuydy MS, Illmer T, et al: Obinutuzumab plus chlorambucil in patients with CLL and coexisting conditions. N Engl J Med 370: 1101-1110, 2014.

10. Brown J, O'Brien S, Kingsley C,Eradat H, Pagel J,Lymp J, Hirata J and Kipps TJ: Obinutuzumab plus fludarabine/cyclophosphamide or bendamustine in the initial therapy of CLL patients: the phase 1b GALTON trial. Blood 125: 2779-2785, 2015.

11. Robak T: Emerging monoclonal antibodies and related agents for the treatment of chronic lymphocytic leukemia. Future Oncol 9: 69-91, 2013.

12. Byrd JC, Pagel JM, Awan FT, Forero A, Flinn IW, Deauna-Limayo DP, Spurgeon SE, Andritsos LA, Gopal AK, Leonard JP, et al: A phase 1 study evaluating the safety and tolerability of otlertuzumab, an anti-CD37 mono-specific ADAPTIR therapeutic protein in chronic lymphocytic leukemia. Blood 123: 1302-1308, 2014.

13. Baum P, Cerveny C, Gordon B, Nilsson C, Wiens J and Rafiq S: Evaluation of the effect of Tru-016, an anti-CD37 directed SMIP in combination with other therapeutic drugs in models of non-Hodgkin's lymphoma. J Clin Oncol 27: Abs. 8571, 2009.

14. Robak T, Hellman A, Kloczko J, Loscertales J, Lech-Maranda E, Pagel J, Mato AR, Byrd JC, Awan F, Hebart H, et al: Phase 2 study of Otlertuzumab (TRU-016), an anti-CD37 ADAPTIR ${ }^{\mathrm{TM}}$ protein, in combination with Bendamustine vs Bendamustine alone in patients with relapsed chronic lymphocytic leukemia (CLL) - updated results. Blood 124: 5642, 2014.

15. Maddocks K, Pagel J, O'Brien S, Byrd J, Stromatt S and Awan F: Phase 1b study of Otlertuzumab (Tru-016), an anti-CD37 ADAPTIR $^{\mathrm{TM}}$ protein, in combination with rituximab in patients with previously untreated chronic lymphocytic leukemia (CLL). Blood (ASH Annual Meeting abstracts): 4165, 2013.

16. Robak T: Emerging monoclonal antibodies and related agents for the treatment of chronic lymphocytic leukemia. Future Oncol 9: 69-91, 2013. 
17. Durand J, Huchet V, Merieau E, et al: Regulatory B Cells with a Partial Defect in CD40 Signaling and Overexpressing Granzyme B Transfer Allograft Tolerance in Rodents. J Immunol 195: 5035-5044, 2015.

18. Dal Bo M, Tissino E, Benedetti D, Caldana C, Bomben R, Del Poeta G, Gaidano G, Rossi FM, Zucchetto A and Gattei V: Microenvironmental interactions in chronic lymphocytic leukemia: The master role of CD49d. Semin Hematol 51: 168-176, 2014.

19. Burger JA and Gribben JG: The microenvironment in chronic lymphocytic leukemia (CLL) and other B cell malignancies: Insight into disease biology and new targeted therapies. Semin Cancer Biol 24: 71-81, 2014.

20. Friedberg JW, Sharman J, Sweetenham J, et al: Inhibition of Syk with fostamatinib disodium has significant clinical activity in non-Hodgkin lymphoma and chronic lymphocytic leukemia. Blood 115: 2578-2585, 2010.

21. Kadia T, Delioukina M, Kantarjian H, Keating M, Wierda W, Burger J, Wieland S and Levitt D: A pilot phase II study of the lyn kinase inhibitor bafetinib in patients with relapsed or refractory B cell chronic lymphocytic leukemia. Blood (ASH Annual Meeting abstracts) 118: 2858, 2011.

22. Herman SE, Gordon AL, Hertlein E, Ramanunni A, Zhang X, Jaglowski S, Flynn J, Jones J, Blum KA, Buggy JJ, et al: Bruton tyrosine kinase represents a promising therapeutic target for treatment of chronic lymphocytic leukemia and is effectively targeted by PCI-32765. Blood 117: 6287-6296, 2011.

23. de Rooij MF, Kuil A, Geest CR, Eldering E, Chang BY, Buggy JJ, Pals ST and Spaargaren M: The clinically active BTK inhibitor PCI-32765 targets B-cell receptor- and chemokine-controlled adhesion and migration in chronic lymphocytic leukemia. Blood 119: 2590-2594, 2012.

24. Burger JA, Keating MJ, Wierda WG, Hartmann E, Hoellenriegel J, Rosin NY, de Weerdt I, Jeyakumar G, Ferrajoli A, Cardenas-Turanzas M, et al: Safety and activity of ibrutinib plus rituximab for patients with high-risk chronic lymphocytic leukaemia: A single-arm, phase 2 study. Lancet Oncol 15: 1090-1099, 2014.

25. O'Brien S, Furman RR, Coutre SE, Sharman JP, Burger JA, Blum KA, Grant B, Richards DA, Coleman M, Wierda WG, et al: Ibrutinib as initial therapy for elderly patients with chronic lymphocytic leukaemia or small lymphocytic lymphoma: An open-label, multicentre, phase $1 \mathrm{~b} / 2$ trial. Lancet Oncol 15: 48-58, 2014

26. Byrd JC, Brown JR, O'Brien S, Barrientos JC, Kay NE, Reddy NM, Coutre S, Tam CS, Mulligan SP, Jaeger U, et al; RESONATE Investigators: Ibrutinib versus ofatumumab in previously treated chronic lymphoid leukemia. N Engl J Med 371: 213-223, 2014.

27. Akinleye A, Chen Y, Mukhi N, Song Y and Liu D: Ibrutinib and novel BTK inhibitors in clinical development. J Hematol Oncol 6: 59,2013

28. Lannutti BJ, Meadows SA, Herman SE, Kashishian A, Steiner B, Johnson AJ, Byrd JC, Tyner JW, Loriaux MM, Deininger M, et al: CAL-101, a p110delta selective phosphatidylinositol-3-kinase inhibitor for the treatment of B-cell malignancies, inhibits PI3K signaling and cellular viability. Blood 117: 591-594, 2011.

29. Brown JR, Byrd JC, Coutre SE, Benson DM, Flinn IW, Wagner-Johnston ND, Spurgeon SE, Kahl BS, Bello C Webb HK, et al: Idelalisib, an inhibitor of phosphatidylinositol 3-kinase $\mathrm{p} 110 \delta$, for relapsed/refractory chronic lymphocytic leukemia. Blood 123: 3390-3397, 2014.

30. Fiorcari S, Brown WS, McIntyre BW,Estrov Z,Maffei R, O'Brien S, Sivina M, Hoellenriegel J, Wierda WG, Keating MJ, et al: The PI3-kinase delta inhibitor idelalisib (GS-1101) targets integrin-mediated adhesion of chronic lymphocytic leukemia (CLL) cell to endothelial and marrow stromal cells. PLoS One 8: e83830, 2013.
31. PattonDT,Garden OA,Pearce WP,CloughLE,Monk CR,Leung E, Rowan WC, Sancho S, Walker LS, Vanhaesebroeck B, et al: Cutting edge: The phosphoinositide 3-kinase p110 delta is critical for the function of CD4+CD25+Foxp3+ regulatory $\mathrm{T}$ cells J Immunol 177: 6598-6602, 2006.

32. O'Brien SM, Lamanna N, Kipps TJ, Flinn I, Zelenetz AD, Burger JA, Holes L, Johnson DM, Gu J, Dansey RD, et al: A phase II study of the selective phosphatidylinositol 3-kinase delta (PI3Kס) inhibitor idelalisib (GS-1101) in combination with rituximab $(R)$ in treatment-naive patients (pts) $\geq 65$ years with chronic lymphocytic leukemia (CLL) or small lymphocytic lymphoma (SLL). J Clin Oncol 31: 7005, 2013.

33. Kipps TJ, Swinnen LJ, Wierda WG, Jones JA, Coutre SE, Smith MR, Yang J, Cui Y, Busman T, Enschede S and Humerickhouse R: Navitoclax (ABT-263) plus fludarabine/cyclophosphamide/ rituximab (FCR) or bendamustine/rituximab (BR): A phase 1 study in patients with relapsed/refractory chronic lymphocytic leukemia (CLL). Blood (ASH Annual Meeting abstracts) 118: 3904, 2011

34. Roberts AW, Ma S, Kipps TJ, Barrientos J, Davids MS and Anderson MA: ABT-199 (GDC- 0199) combined with rituximab $(R)$ in patients (pts) with relapsed/refractory $(R / R)$ chronic lymphocytic leukemia (CLL): Interim results of a phase 1b study. J Clin Oncol 32: 5s, 2014

35. Johnson AJ, Yeh YY, Smith LL, Wagner AJ, Hessler J, Gupta S, Flynn J, Jones J, Zhang X, Bannerji R, et al: The novel cyclin-dependent kinase inhibitor dinaciclib (SCH727965) promotes apoptosis and abrogates microenvironmental cytokine protection in chronic lymphocytic leukemia cells. Leukemia 26: 2554-2557, 2012.

36. Flynn J, Andritsos LA, Jones JA, Johnson AJ, Maddocks K Wiley E, Small K, Im EK, Grever MR, Bannerji R, et al: Dinaciclib (SCH 727965) is a novel Cyclin-Dependent Kinase (CDK) inhibitor that exhibits activity in patients with relapsed or refractory Chronic Lymphocytic Leukemia (CLL). Blood (ASH Annual Meeting abstracts) 122: 871, 2013

37. Lin TS, Ruppert AS, Johnson AJ, Fischer B, Heerema NA, Andritsos LA, Blum KA, Flynn JM, Jones JA, Hu W, et al: Phase II study of flavopiridol in relapsed chronic lymphocytic leukemia demonstrating high response rates in genetically high-risk disease. J Clin Oncol 27: 6012-6018, 2009.

38. Wang JC, Kafeel MI, Avezbakiyev B, Chen C, Sun Y, Rathnasabapathy C, Kalavar M, He Z, Burton J and Lichter S: Histone deacetylase in chronic lymphocytic leukemia. Oncology 81: 325-329, 2011.

39. Sampath D, Liu C, Vasan K, Sulda M, Puduvalli VK, Wierda WG and Keating MJ: Histone deacetylases mediate the silencing of miR-15a, miR-16, and miR-29b in chronic lymphocytic leukemia. Blood 119: 1162-1172, 2012

40. Bonfils C, Kalita A, Dubay M, Siu LL, Carducci MA, Reid G, Martell RE, Besterman JM and Li Z: Evaluation of the pharmacodynamic effects of MGCD0103 from preclinical models to human using a novel HDAC enzyme assay. Clin Cancer Res 14: 3441-3449, 2008.

41. El-Khoury V, Pierson S, Szwarcbart E, Brons NH, Roland O, Cherrier-De Wilde S, Plawny L, Van Dyck E and Berchem G: Disruption of autophagy by the histone deacetylase inhibitor MGCD0103 and its therapeutic implication in B-cell chronic lymphocytic leukemia. Leukemia 28: 1636-1646, 2014. 